\title{
Cimetidine Quantification in Human Plasma by High-perfor- mance Liquid Chromatography Coupled to Electrospray Ionization Tandem Mass Spectrometry. Application to a Comparative Pharmacokinetics Study
}

\author{
Moreno RA ${ }^{1,2}$, Oliveira Costal ${ }^{3}$, Brum Junior $\mathrm{L}^{4}$, Sverdloff $\mathrm{CE}^{1,2}$, \\ Domingues CC ${ }^{1}$, Borges DC $^{5}$, Oliveira RA', Borges NC ${ }^{1,6 *}$ \\ ${ }^{1}$ Synchrophar Assessoria e Desenvolvimento de Projetos Clínicos, Campinas, SP, Brazil \\ ${ }^{2}$ Department of Pharmacology, Faculty of Medical Sciences, State University of Campinas (UNICAMP), Campinas, SP, Brazil \\ ${ }^{3}$ Department of Bioequivalence, Hermes Pardini Institute, Belo Horizonte, MG, Brazil \\ ${ }^{4}$ Multilab Indústria e Comércio de Produtos Farmacêuticos Ltda, São Jerônimo, RS, Brazil \\ ${ }^{5}$ Jundiai Faculty of Medicine, Jundiai, SP, Brazil \\ ${ }^{6}$ Department of Internal Medicine, Faculty of Medical Sciences, State University of Campinas, SP, Brazil
}

\begin{abstract}
A specific, fast and sensitive LC-MS/MS assay was developed for the determination of cimetidine in human plasma using nizatidine as the internal standard (IS). The limit of quantification was $5.0 \mathrm{ng} / \mathrm{ml}$ and the method was linear in the range of 5.0 to $5000 \mathrm{ng} / \mathrm{ml}$. The cimetidine and IS retention times were $1.35 \pm 0.3$ and $1.40 \pm 0.03 \mathrm{~min}$, respectively. Method intra-batch precision and accuracy ranged from 2.0 to $5.4 \%$, and 92.1 to $103.7 \%$, respectively. Inter-batch precision ranged from 4.2 to $6.3 \%$, while Inter-batch accuracy ranged from 97.0 to $106.6 \%$.

The analytical method was applied to evaluate the pharmacokinetic and relative bioavailability of two different pharmaceutical formulations containing $400 \mathrm{mg}$ of cimetidine containing. This study evaluated 29 volunteers in a randomized, 2-period crossover study with 14 days washout period between doses. The geometric mean and respective $90 \% \mathrm{CI}$ of cimetidine test/reference percent ratios were $95.73 \%$ (87.76 - 104.43\%) for $\mathrm{C}_{\max }, 100.80 \%$ (95.98 - 105.96\%) for $\mathrm{AUC}_{0-\mathrm{t}}$ and $100.90(96.06-105.88)$ for $\mathrm{AUC}_{0 \text {-inf }}$ Based on the $90 \%$ confidence interval of the individual ratios (test formulation/reference formulation) for $\mathrm{C}_{\max }$ and $\mathrm{AUC}_{0 \text {-inf }}$ it was concluded that the test formulation is bioequivalent to the reference one with respect to the rate and extent of absorption of cimetidine. In addition, using the Kruskal-Wallis Test no statistical differences of Tmax and the Cmax were observed related to the sex of the volunteer.
\end{abstract}

Keywords: Cimetidine; Pharmacokinetics; HPLC; Mass spectrometry; Bioavailability

\section{Introduction}

Cimetidine, $N^{\prime \prime}$-cyano- $N$-methyl- $N^{\prime}$-[2 ([(5-methyl-1Himidazol-4-yl) methyl] thio) ethyl] guanidine (Figure 1a), is a histamine H2-receptor antagonist (Somogyi et al., 1983) which inhibits the secretion of gastric acid. It is extensively used in the treatment of peptic ulcers, in the management of reflux oesophagitis and for the inhibition of gastric acid secretion associated with Zollinger-Ellison syndrome. Cimetidine inhibits various hepatic enzymes responsible for drug metabolism J Bioanal Biomed
(Somogyi et al., 1982). Cimetidine has also been identified as a substrate for P-glycoprotein (P-GP), an MDR-encoded membrane transporter that is expressed in normal tissues including kidney proximal tubules (Fojo et al., 1987; Karyekar et al., 2003; Thiebaut et al., 1987). It is rapidly absorbed following oral administration, peak plasma levels being attained after approximately two hours when taken with food, and after one hour when taken without food. It is about $15-20 \%$ protein-bound, with a plasma half-life of about two hours and about two thirds of the oral dose is excreted within $24 \mathrm{~h}$. Cimetidine is excreted predominantly unchanged by the kidneys (approximately 70\%) and undergoes extensive tubular secretion with renal clearance values approximately four-fold greater than creatinine clearance

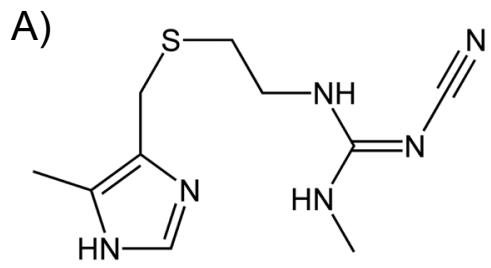

B)

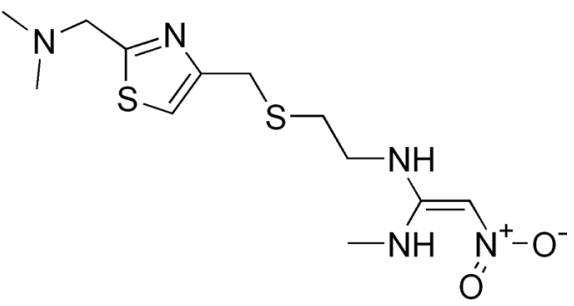

Figure 1: Chemical structure of cimetidine (A) and nizatidine (B).

*Corresponding author: Ney Carter C. Borges, 24 Cesar Bierrenbach Street, Campinas, SP, Brazil, Postal Code: 13015-025; Tel/Fax: 5519 3234-2834; E-mail: medney@synchrophar.com

Received September 11, 2009; Accepted December 14, 2009; Published December 15, 2009

Citation: Moreno RA, Costal O, Brum Junior L, Sverdloff CE, Domingues CC, et al. (2009) Cimetidine Quantification in Human Plasma by Highperformance Liquid Chromatography Coupled to Electrospray Ionization Tandem Mass Spectrometry. Application to a Comparative Pharmacokinetics Study. J Bioanal Biomed 1: 005-013. doi:10.4172/1948593X.1000002

Copyright: (C) 2009 Moreno RA, et al. This is an open-access article distributed under the terms of the Creative Commons Attribution License, which permits unrestricted use, distribution, and reproduction in any medium, provided the original author and source are credited. 
Citation: Moreno RA, CostaI O, Brum Junior L, Sverdloff CE, Domingues CC, et al. (2009) Cimetidine Quantification in Human Plasma by High-performance Liquid Chromatography Coupled to Electrospray Ionization Tandem Mass Spectrometry. Application to a Comparative Pharmacokinetics Study. J Bioanal Biomed 1: 005-013. doi:10.4172/1948-593X.1000002

(Berardi et al., 1988; Pedersen et al., 1980). Cimetidine does not cross the blood-brain barrier, but does cross the placental barrier and is excreted in milk. It is usually administered in divided doses of up to $1600 \mathrm{mg}$ daily.

Several investigations concerning the determination of cimetidine in biological fluids have been reported. Due to its highly polar nature, cimetidine is normally determined by reversed-phase HPLC. Several methods for the determination of cimetidine in human plasma have been reported using HPLC with ultraviolet (UV) detection (Abdel-Rahim et al., 1985; Chiou et al., 1986; Hempenius et al., 1998; Kelly et al., 1995; Larsen et al., 1979; Russel et al., 1994; Strong et al., 1987), and using capillary electrophoresis (CE) with UV (Luksa et al., 1995; Luo et al., 2001). Most methods utilized either solid-phase extraction or liquid-phase extraction techniques. Limitations of these methods include the time consuming and complicated sample preparation procedures, such as multiple steps of extraction, solvent evaporation, and sample reconstitution and a protonation step using hydrochloric acid (Abdel-Rahim et al., 1985), the requirement to extract large volumes of plasma (0.5-1.0 ml) (Lin et al., 1985; Lorenzo et al., 1981; Ziemniak et al., 1981), low or inconsistent recovery in plasma (Kelly et al., 1995; Soldin et al., 1979), the limit of quantitation is relatively high, and/or the dynamic range of the calibration curve is relatively narrow. A more sensitive method using HPLC coupled to atmospheric pressure chemical ionization (APCI) tandem mass spectrometer was developed by Xu et al., (1999) to quantify cimetidine in human plasma.

The main objective of this study was to develop and validate a fast, sensitive and robust method to quantify cimetidine in human plasma using nizatidine as the internal standard (IS). The method was based on the use of liquid chromatography (LC) coupled with electrospray ionization (ESI) and selected reaction monitoring (SRM) mass spectrometry. The method has been successfully used to analyze samples from a pharmacokinetics study comparing the oral bioavailability in healthy human volunteers of two $400 \mathrm{mg}$ cimetidine tablet formulation.

\section{Experimental Methods}

\section{Chemicals and materials}

Cimetidine was acquired from the US Pharmacopeia (batch 11C081) and nizatidine (Figure 1b) was purchased from SigmaAldrich (USA) as Chemical Reference Standards (batch 056K1398).

Acetonitrile, ethyl acetate, formic acid and ammonium hydroxide were all of analytical grade and were purchased from Carlo Erba do Brasil (Brasil). Normal and hyperlipemic human Plasma was obtained from Hemoservice (MG, Brasil) and hemolyzed human plasma was obtained from Institute Hermes Pardini (MG, Brasil). All plasma samples came from distinct drug free subjects (six different lots).

\section{Chromatographic conditions}

The liquid chromatography experiments were performed on an Alliance HT, Waters 2795 system using a Nova-Pack C18, $4 \mu \mathrm{m}$ analytical column $(150 \times 3.9 \mathrm{~mm}$ i.d. $)$ operating at $30+5^{\circ} \mathrm{C}$. Cimetidine and nizatidine were eluted isocratically with acetonitrile/water mixture (65:35, v/v) with $10 \mathrm{mM}$ formic acid and J Bioanal Biomed
$15 \mathrm{mM}$ ammonium hydroxide. The total run time was 3 min using a controlled elution at 1000-1100 psi and a flow rate of 0.8 $\mathrm{ml} / \mathrm{min}$. The retention times were $1.35 \pm 0.3$ and $1.40 \pm 0.03 \mathrm{~min}$ for cimetidine and nizatidine, respectively.

\section{Mass spectrometric conditions}

The LC equipment was connected to a mass spectrometer Quattro-Micro API system (Waters, USA) equipped with an Electrospray ionization source using operated at positive ion mode and multiple reactions monitoring (MRM) mode.

The tuning parameters were optimized for cimetidine and nizatidine by infusing the standard solution of each compound into the stainless steel sample capillary of the electrospray source. Interface parameters were optimized as follows: source temperature $120^{\circ} \mathrm{C}$, desolvation temperature $500^{\circ} \mathrm{C}$, cone voltage $25 \mathrm{~V}$, capillary $3.5 \mathrm{kV}$ and dwell time of $0.3 \mathrm{~s}$ for each transition. Tandem mass spectrometric analysis was performed using nitrogen as collision gas as collision energy at $15.0 \mathrm{eV}$ for cimetidine acetate and $18.0 \mathrm{eV}$ for nizatidine. Based on the full scan MS/ MS spectrum of each drug, the most abundant ions were selected and the mass spectrometer was set to monitor the transitions of the precursors to the product ions, as follows: $\mathrm{m} / \mathrm{z} 253.20 \rightarrow$ 159.10 for cimetidine and $\mathrm{m} / \mathrm{z} 332.20 \rightarrow 154.85$ for nizatidine (precursor and product ion fragments). Data acquisition and analysis were performed using the Waters MassLynx Software.

\section{Drug standards solutions}

Standard stock solutions $(10 \mathrm{ml})$ of cimetidine and nizatidine were prepared, from separate weighting, in acetonitrile/water (50/ $50 \mathrm{v} / \mathrm{v}$ ) at concentration of $1.0 \mathrm{mg} / \mathrm{ml}$, transferred to polypropylene screw cap FalconTM tubes from Becton Dickinson (Mountainview, CA) and kept at $-20^{\circ} \mathrm{C}$. Intermediary solutions of cimetidine acetate and nizatidine were prepared in acetonitrile/water $(50 / 50 \mathrm{v} / \mathrm{v})$, by appropriate dilution of stock solutions.

All calibration curve samples (non-zero samples), except blank plasma, were prepared by spiking different blank plasma batches of the intermediary cimetidine acetate solutions, to yield final plasma concentrations of $5.0 ; 50.0 ; 250.0 ; 100.0 ; 2000.0 ; 3000.0$; 4000.0 , and $5000.0 \mathrm{ng} / \mathrm{ml}$.

\section{Quality control(QC) samples}

The QCs samples were prepared by spiking different blank plasma aliquots with the corresponding cimetidine acetate intermediary standard solution to produce a final concentration equivalent to 0.3 (LQC), 20 (MQC), and $40 \mathrm{ng} / \mathrm{ml}$ (HQC) of cimetidine.

Quality control samples were prepared in blank plasma using a separate set of cimetidine work solution to obtain the final concentrations of 5.0, 15.0, 2100.0 and $4200 \mathrm{ng} / \mathrm{ml}$ for cimetidine (Lower Limit of Quantification-LLOQ, Low Quality controlLQC, Medium Quality control-MQC and High Quality controlHQC, respectively). The spiked plasma samples (standards and quality controls) were extracted in each analytical batch along with the unknown samples. The internal standard nizatidine was added to the final concentration of $2500 \mathrm{ng} / \mathrm{ml}$ in all standard curve, QC and unknown samples.

The standard calibration curves were constructed using the 


\section{Journal of Bioanalysis \& Biomedicine - Open Access \\ JBABM/Vol.1 Issue 1}

peak area ratios of cimetidine analytes and IS vs cimetidine nominal concentrations of the eight plasma standards in duplicate. Linear regression analysis was performed to assess the linearity. In addition, a blank (non-spiked sample) and a zero plasma sample (only spiked with IS) were run to eliminate the presence of interferences.

\section{Sample extraction}

The analyte was extracted from plasma samples, using a single liquid/liquid extraction technique. For sample preparation, 200 $\mu \mathrm{l}$ aliquot of unknown plasma samples (extracted along with the calibration standards and QCs) were transferred to polypropylene tubes (Eppendorff), then $50 \mu \mathrm{l}$ of IS $(10 \mu \mathrm{g} / \mathrm{ml})$ was added each sample. After vortex mixing for $10 \mathrm{~s}$, ethyl acetate was added $(1.5 \mathrm{ml})$ to all the tubes and extraction was performed by vortex mixing for $30 \mathrm{~s}$. Samples were centrifuged at $2000 \mathrm{~g}$ for $5 \mathrm{~min}$ at $4^{\circ} \mathrm{C}$ and frozen at $-70^{\circ} \mathrm{C}$ for $15 \mathrm{~min}$. The organic phase was transferred to another set of clean glass tubes and evaporated to dryness under $\mathrm{N} 2$ at $40^{\circ} \mathrm{C}$ for $10 \mathrm{~min}$. The dry residues were reconstituted in $200 \mu \mathrm{l}$ of acetonitrile/water (65:35, v/v), vortex mixed for $20 \mathrm{~s}$, pipette transferred to injection vials and accommodated in the auto-injector maintained at $5 \pm 3^{\circ} \mathrm{C}$.

\section{Method validation}

Validation of the analytical method was based on the FDA guidance: "Guidance for industry: Bioanalytical Method Validation, US Department of Health and Human Services, Food and Drug Administration, Center for Drug Evaluation and Research (CDER), Center for Biologics Evaluation and Research (CBER), Rockville (May 2001)".

\section{Specificity}

Presence of non-specific peaks and interference from plasma components were evaluated in six different matrices: 4 different sources of normal plasma as well as lipemic and hemolized. All samples were processed by the liquid-liquid extraction procedure and chromatographed to determine the extent to which endogenous plasma components may contribute to the interference at retention time of analyte and internal standard. On the day of the study, all volunteers had a blank plasma sample collected before drug administration. Any interference at the analyte and IS retention time should not account for more than $20 \%$ of LLOQ and $5 \%$ of the peak response area in the concentration used in the method, respectively.

\section{Linearity}

Calibration curves were constructed using eight non-zero standard points covering the range of 5.0 to $5000.0 \mathrm{ng} / \mathrm{ml}$. In addition, a blank (non-spiked sample) and a zero plasma sample (only spiked with IS) were run to discard the presence of interferences. Plasma samples were spiked in duplicates at concentrations of $0.1,0.2,1,2,5,10,30$ and $50 \mathrm{ng} / \mathrm{ml}$ and the samples were extracted as described above. The standard calibration curves for cimetidine were constructed using the analyte/IS peak-area ratios versus nominal concentrations of the analytes. Linear leastsquare regression analysis, with weighting factor of $1 / x$, was performed to assess the linearity, as well as to generate the standard calibration equation: $y=a x+b$, where $y$ is the peak-area ratio, $x$ the concentration, $a$ the slope and $b$ is the intercept of the regression line.

\section{Recovery}

Spiked plasma samples were assayed using five replicates at three concentration levels (LQC, MQC and HQC) and extracted as already described (item 2.6). The recovery (extraction efficacy) was calculated by comparing the peak-area of the extracted sample to that of the unextracted pure authentic standard solutions.

\section{Precision and accuracy}

Precision and accuracy of this method were evaluated using three different batches of LQC, MQC, and HQC of cimetidine, also including the lowest limit of quantification, LLOQ. For intra-batch assay precision and accuracy, six replicates of quality control samples at the three concentration levels were assayed all at once within a day to obtain \% CV and accuracy values. The inter-batch assay precision and accuracy were determined by analyzing mean values of quality control samples from three plasma batches, yielding the corresponding inter-batches $\% \mathrm{CV}$ and accuracy values. The $\% \mathrm{CV}$ determined at each concentration level should not exceed $15 \%$, except at the limit of quantification.

The lower limit of quantification (LLOQ) was determined for cimetidine based on two criteria: (a) the analyte response at LLOQ had to be at least five times baseline noise; (b) the analyte response at LLOQ being determined with sufficient precision and accuracy, i.e., precision of $20 \%$ and accuracy of $80-120 \%$. Calculations were based on five replicates of three blank plasma batches.

\section{Stability assays}

All stability assays were performed using five replicates of plasma spiked with clozapine at low and high QCs concentrations. To be considered stable, the final results should reach the following acceptance condition: the $\% \mathrm{CV}$ of both precision and accuracy determined at each concentration level should not exceed $15 \%$. The percent of degradation was defined comparing sample concentration to the mean values obtained from fresh prepared ones at equivalent concentration. During the validation the following stability parameters were evaluated: Post-processing stability at room temperature for $72 \mathrm{~h}$, three cycles of freeze-thaw, short term storage stability at room temperature for $22 \mathrm{~h}$ and long term storage stability at $-20^{\circ} \mathrm{C}$ during 112 days.

Internal standard and stock solutions in methanol were prepared and stored at $5 \pm 3^{\circ} \mathrm{C}$. Sample aliquots of five replicates of low and high QCs levels were evaluated after sitting for 90 days at $5 \pm 3^{\circ} \mathrm{C}$ for cimedidine and 24 days for nizaditine.

\section{Test products}

A validated HPLC-MS-MS method was applied to evaluate the comparative bioavailability of two $400 \mathrm{mg}$ cimetidine tablets (test cimetidine against the reference formulation).

\section{Subjects}

Twenty nine volunteers of both sexes, aged between 19 and 46 years and within $15 \%$ variation in the ideal body weight were selected for the study. The study group consisted of individuals with the following characteristics (mean $\pm \mathrm{SD}$ ): $31.0 \pm 7.5$ years, IMC $23.8 \pm 1.9 \mathrm{~kg} / \mathrm{m}^{2}$ (range $\left.19.6-26.8 \mathrm{Kg} / \mathrm{m}^{2}\right)$, height between 1.5 and $1.9 \mathrm{~m}(1.7 \pm 0.1 \mathrm{~cm})$ and weighing between 46.0 and

Volume 1(1) : 005-013 (2009) - 07 
Citation: Moreno RA, CostaI O, Brum Junior L, Sverdloff CE, Domingues CC, et al. (2009) Cimetidine Quantification in Human Plasma by High-performance Liquid Chromatography Coupled to Electrospray Ionization Tandem Mass Spectrometry. Application to a Comparative Pharmacokinetics Study. J Bioanal Biomed 1: 005-013. doi:10.4172/1948-593X.1000002

$87.0 \mathrm{~kg}(66.5 \pm 12.2 \mathrm{~kg})$. All volunteers were free from significant cardiac, hepatic, renal, pulmonary, neurological, gastrointestinal, and hematological diseases, as assessed by general physical examination, ECG, and the following laboratory tests: blood glucose, urea, uric acid, creatinine, aspartate aminotransferase (AST), alanine aminotransferase (ALT), alkaline phosphatase, L- $\gamma$-glutamyl-transferase $(\gamma$-GT), total bilirubin, albumin and total protein, tryglicerides, total cholesterol, hemoglobin, hematocrit, platelet count, total and differential white cell counts, feces parasitological examination and routine urinalysis. All subjects were negative for HIV, HBV (except for serological scar) and HCV. All female volunteers were negative for pregnancy test ( $\beta \mathrm{HCG})$.

The study was conducted in accordance with the provisions of the Declaration of Helsinki (1964), Tokyo (1975), Venice (1983), Hong Kong (1989), Somerset West (1996), Edinburgh (2000) revisions and the Resolutions No.196/96 and 251/97 of National Health Council - Health Ministry, Brazil. The clinical protocol was also approved by the State University of Campinas ethic's committee and all participants provided written, informed consent.

\section{Study design}

The study was conducted in an open, randomized, single crossover balanced design with 14 days washout period between doses. During each period, the volunteers were hospitalized at 8:00 p.m. having an evening meal at 8:30. After an overnight fast the group 1 received the medication starting at 7:00 a.m without any additional meal. All volunteers received a single $400 \mathrm{mg}$ tablet orally corresponding to the test cimetidine or reference formulation. Water $(200 \mathrm{ml})$ was given immediately after drug administration. All volunteers were required to remain fasting until four hours after dose when a standard meal was provided after five (lunch), eight (coffee break), twelve hours after dosing (evening meal). No other food was permitted during the "in-house" period. Liquid consumption was permitted ad libitum six hours before and two hours after drug administration, but xanthinecontaining drinks including tea, coffee, and cola were prohibited. Food was also xanthine-free. Smoking was prohibited during the "in-house" period. All subjects were requested to stay in the clinic for a $24 \mathrm{~h}$ period after drug administration.

For the cimetidine quantification blood samples $(7.5 \mathrm{ml})$ from a suitable antecubital vein were collected by indwelling catheter into heparin containing tubes before and $0: 10 \mathrm{~h}, 0: 20 \mathrm{~h} 0: 30 \mathrm{~h}$, 0:45h, 1h, 1:15h 1:30h, 1:45h, 2h, 2:20h, 2:40h, 3h, 3:30h, 4h, $5 \mathrm{~h}, 6 \mathrm{~h}, 8 \mathrm{~h}, 10 \mathrm{~h}, 14 \mathrm{~h}$ and $24 \mathrm{~h}$ after administration. All blood samples were centrifuged at approximately $2000 \mathrm{x} g$ for $10 \mathrm{~min}$ at $4^{\circ} \mathrm{C}$ and the plasma stored at $-20^{\circ} \mathrm{C}$ until assayed for cimetidine content.

\section{Pharmacokinetic analysis}

Bioequivalence between the two formulations was calculated for both oral suspension study and tablet formulation study by calculating individual test/reference ratios for the peak of concentration $\left(\mathrm{C}_{\max }\right)$, area under curve (AUC) of plasma concentration until the last concentration observed $\left(\mathrm{AUC}_{0-\mathrm{t}}\right)$, and the area under curve between the first sample (pre-dosage) and infinite

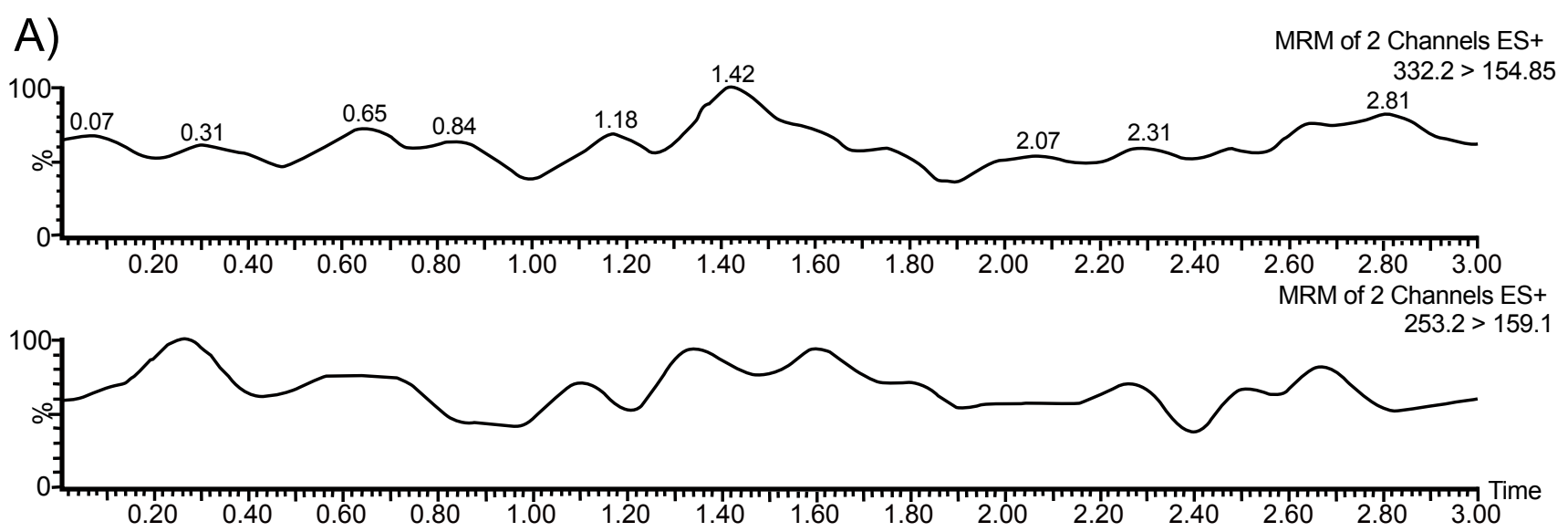

B)
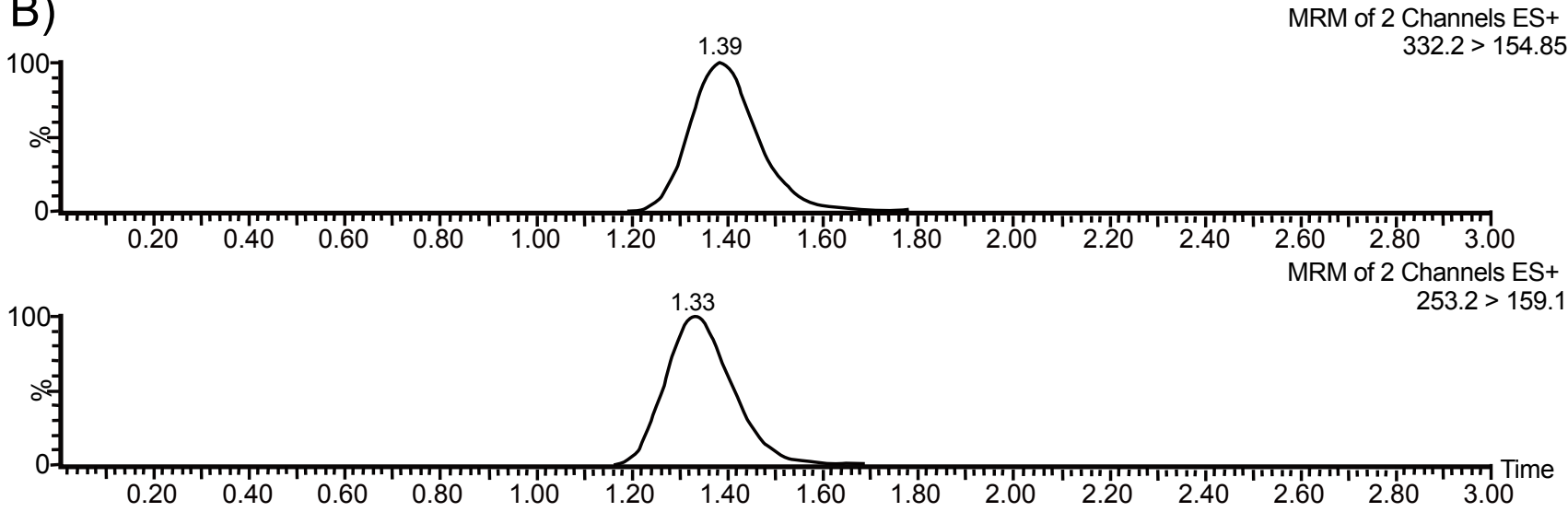

Figure 2: MRM chromatograms of human plasma samples spiked with cimetidine or IS (nizatidine). Left panels show the monitoring channel for CYP acetate and right panels shows the monitoring channel for IS. (A) blank plasma samples; (B) plasma samples spiked with cimetidine at LLOQ concentration (5 ng/ml) and IS. 
$\left(\mathrm{AUC}_{\text {inf }}\right)$. The $\mathrm{C}_{\text {max }}$ and the time taken to achieve this concentration $\left(\mathrm{T}_{\max }\right)$ were obtained directly from the curves. The first-order terminal elimination rate constant (ke) was estimated by linear regression from the points describing the elimination phase in a log-linear plot. Half-life $\left(\mathrm{t}_{1 / 2}\right)$ was derived from this rate constant $\left(t_{1 / 2}=\ln (2) / k e\right)$. The areas under the cimetidine plasma concentration vs. time curves from 0 -to the last detectable concentration $\left(\mathrm{AUC}_{0-\mathrm{t}}\right)$ were calculated by applying the linear trapezoid rule. Extrapolation of these areas to infinity $\left(\mathrm{AUC}_{\mathrm{inf}}\right)$ was done by adding the value $\mathrm{C}_{\text {last }} / \mathrm{ke}$ to the calculated $\mathrm{AUC}_{0-\mathrm{t}}$ (where $\mathrm{C}_{\text {last }}=$ the last detectable concentration). The AUC and $\mathrm{C}_{\max }$ data for the two formulations were analyzed by ANOVA to establish whether the $90 \%$ CI of the ratios was within the $80-125 \%$ interval indicating bioequivalence as proposed by the US Food and Drug Administration. Parametric analyses of $\ln$-transformed arithmetic means between test and reference formulations were also performed. The non-parametric Kruskal-Wallis test was used to evaluate the influence of sex distribution on the pharmacokinetics parameters, mainly the $\mathrm{T}_{\max }$ and $\mathrm{C}_{\max }$. The software used included R2.2, Microsoft Excel 97, Tinn-R 1.1, Win-Edit 2.0, Scientific Work Place 5.0 and Equivtest 2.0.

\section{Results}

\section{Validation results}

All sample analysis were carried out in a GLP-compliant manner and therefore the LC-MS/MS methods need to be carried out according to the current Brazilian Regulatory Agency (ANVISA), yet in accordance to US Food and Drug Administration Bioanalytical method validation guidance.

\section{Assessment of linearity and specificity}

Linearity was tested for the range of concentrations $5.0-$ $5000.0 \mathrm{ng} / \mathrm{ml}$, showing good linear response to the method. Correlation coefficient ranged from 0.996962 to 0.997839 . The chromatograms obtained from LLOQ and extracted blank plasma samples are depicted in Figure 2. The cimetidine and IS retention times were $1.35 \pm 0.3$ and $1.40 \pm 0.3 \mathrm{~min}$, respectively. Specificity of the response for the interfering peaks at the same retention time of the drug were less than $20 \%$ of the LLOQ response, when analyzing the blank normal plasma, and the two other batches of hemolysed and hyperlipidemic plasma (Figure 3). The response for the interfering peaks at the retention time of the internal standard was also less than $20 \%$, considering the response in the concentration used. Furthermore, blank plasma samples from all volunteers were run before unknown sample quantification, showing a clear chromatogram. The main reason was the clean liquid-liquid extraction besides the high selectivity of the MRM mode on LC-MS-MS spectrometer. Therefore, the high selectivity of the method was confirmed by both drug and IS, as no endogenous peaks were seen at analytical conditions previously described.

\section{Recovery of cimetidine}

Absolute recoveries for both cimetidine and IS were evaluated, according to Section 2.7.3. Results of sample extraction procedure showed an overall mean value of 78.8\% (\% CV 3.9). At different QCs levels (Low, Medium and High) it was as follows: 75.3 (\% CV 3.9), 81.2 (\% CV 5.3), and 79.9\% (\% CV 4.4), respectively. The IS recovery was $52.9 \%$ (\% CV 10.6),
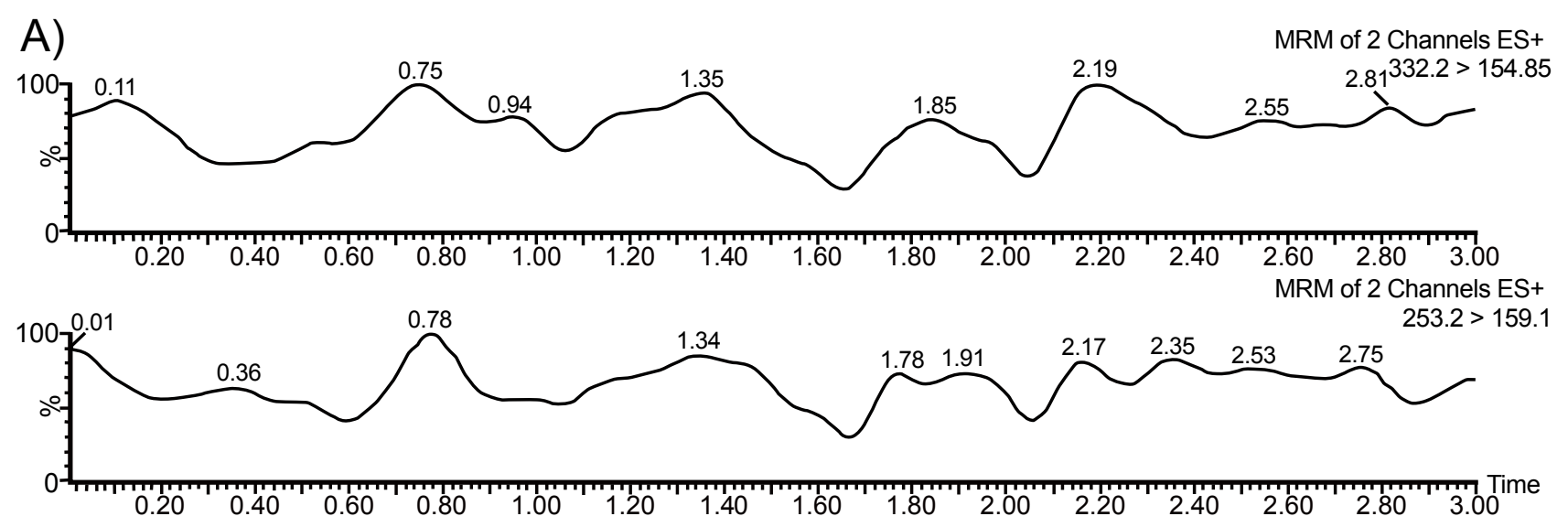

B)
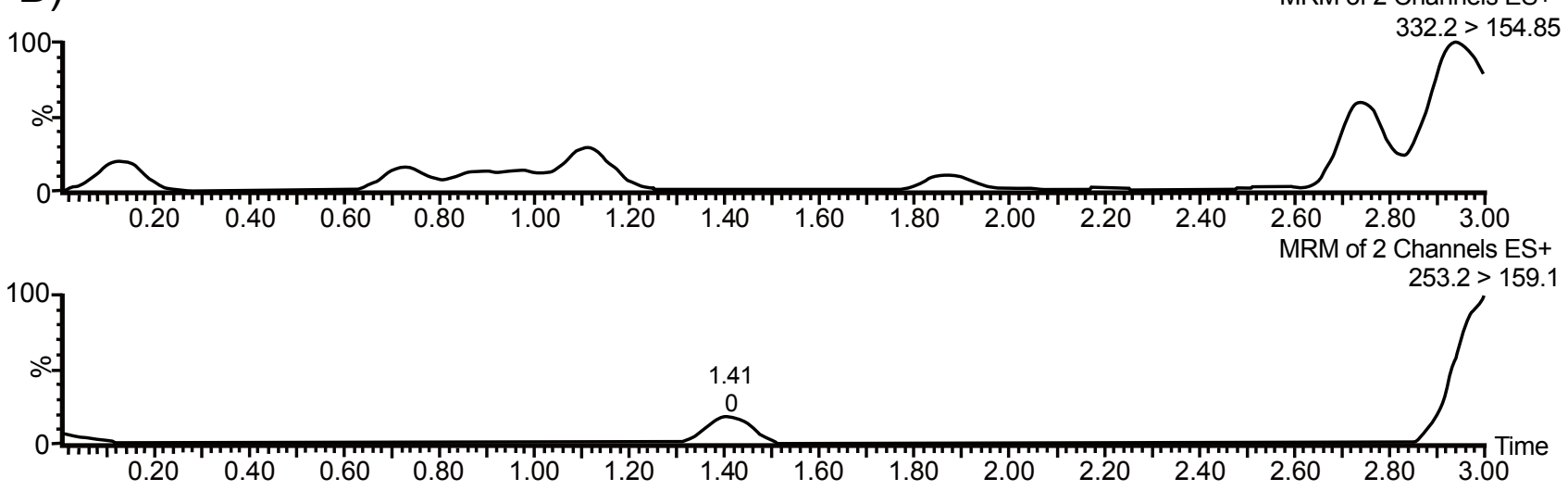

Figure 3: Specificity of the response for the interfering peaks at the retention time for cimetidine and nizatidine. MRM Chromatograms of blank plasma samples at both cimetidine and nizatidine channels: (A) hyperlipemic and (B) hemolyzed plasma sample. 
Citation: Moreno RA, CostaI O, Brum Junior L, Sverdloff CE, Domingues CC, et al. (2009) Cimetidine Quantification in Human Plasma by High-performance Liquid Chromatography Coupled to Electrospray Ionization Tandem Mass Spectrometry. Application to a Comparative Pharmacokinetics Study. J Bioanal Biomed 1: 005-013. doi:10.4172/1948-593X.1000002

showing a very efficient and selective extraction procedure.

\section{Accuracy and precision measurement}

Intra-batch precision and accuracy of the assay was measured for Cimetidine and IS at each QC level (15.3, 2100.0 and 4200.0 $\mathrm{ng} / \mathrm{ml}$ ). Method intra-batch precision and accuracy (\% CV) ranged from 2.0 to $2.7 \%$, and 92.1 to $103.7 \%$, respectively. Method inter-batch precision (\% CV) and accuracy ranged from 4.2 to $6.2 \%$, and 97.0 to $106.6 \%$, respectively, as presented in Table 1.

These results were within the acceptance criteria for precision and accuracy, i.e., deviation values were within $\pm 15 \%$ of the authentic values, except for LLOQ, which could show a $\pm 20 \%$ deviation. For sensitivity determination, the lower limit of quantification (LLOQ) for cimetidine was found to be $5.0 \mathrm{ng} / \mathrm{ml}$. The intra-batch precision and accuracy (\% CV) were 5.42 and 99.3 , respectively, while the inter-batch precision and accuracy $(\% \mathrm{CV})$ were 6.3 and $104.1 \%$, respectively.

\section{Stock solution stability}

Following ninety days of cimetidine storage in acetonitrile/ water $(50 / 50 \mathrm{v} / \mathrm{v})$, differences in analysis of stored and fresh stock solutions were $-1.9 \%$ (\% CV of $1.7 \%$ for initial and $3.2 \%$ for final concentration) for low QC, and 6.2\% (\% CV of $1.9 \%$ for initial and $2.5 \%$ for final concentration) for high QC samples. IS samples were analyzed after twenty four days and showed a variation of $0.4 \%$ (\% CV of $1.2 \%$ for initial and $2.2 \%$ for final concentration). All of them were within analytical method acceptance criteria, i.e., not higher than $15 \%$ of fresh solutions.

\section{Short term stability}

Twenty two hours cimetidine stability in plasma was assessed as describe in methods. After extraction procedure and kept for $22 \mathrm{~h}$ at room temperature, differences in analysis of stored and fresh stock solutions were $-1.4 \%$ (\% CV of $4.7 \%$ for initial and $3.6 \%$ for final concentration) for low QC, and $-15.0 \%$ (\% CV of $2.0 \%$ for initial and $2.7 \%$ for final concentration) for high QC samples. Therefore, the difference between fresh and stored samples was within allowed variability range.

\section{Post-processing stability}

After thaw, extraction and $72 \mathrm{~h}$ sitting in the autosampler, stability assessment of samples showed a reliable stability behavior under such conditions. After analysis of both fresh and stored samples, differences in analysis $2.3 \%$ (\% CV of $2.6 \%$ for initial and $2.6 \%$ for final concentration) for low QC, and 3.3\% (\% CV of $3.0 \%$ for initial and $1.9 \%$ for final concentration) for high QC samples.

\section{Freeze/thaw conditions}

Data representing cimetidine concentration at the end of the third thaw cycle are summarized in Table 2 . It shows that both analyte and IS analysis are stable at such experimental conditions.

\section{Long term storage stability}

Data representing cimetidine concentration at the end of the long term storage stability are summarized in Table 3. It shows that analyte analysis is stable after 112 days at $-20^{\circ} \mathrm{C}$.

\begin{tabular}{|c|c|c|c|c|}
\hline & $\begin{array}{c}\text { Intra-run } \\
\text { accuracy }^{\mathrm{a}}\end{array}$ & $\begin{array}{c}\text { Inter-run } \\
\text { accuracy }^{\mathrm{b}}\end{array}$ & $\begin{array}{c}\text { Intra-run } \\
\text { precision }^{\mathrm{c}}(\% \mathrm{CV})\end{array}$ & $\begin{array}{c}\text { Inter-run } \\
\text { precision }^{\mathrm{b}}(\% \mathrm{CV})\end{array}$ \\
\hline \multicolumn{5}{|c|}{ QC samples } \\
\hline LLOQ & 99.3 & 104.1 & 5.4 & 6.3 \\
\hline LQC & 103.7 & 106.6 & 2.7 & 4.2 \\
\hline MQC & 102.1 & 103.4 & 2.6 & 6.2 \\
\hline HQC & 92.1 & 97.0 & 2.0 & 5,5 \\
\hline
\end{tabular}

${ }^{a}(n=6)$, expressed as (found concentration / nominal concentration) x 100

${ }^{b}$ Values obtained from all replicates $(\mathrm{n}=18)$ ${ }^{c} n=6$

Table 1: Accuracy and precision data for cimetidine quantification in human plasma. Results were obtained during the validation of QC samples, including the LLOQ, in human plasma.

\begin{tabular}{|c|l|l|l|l|l|}
\hline & \multicolumn{1}{|c|}{$\begin{array}{c}\text { Initial mean } \\
\text { conc.(ng/ml) }\end{array}$} & $\% \mathrm{CV}$ & $\begin{array}{c}\text { Final mean } \\
\text { conc. } \\
(\mathrm{ng} / \mathrm{ml})\end{array}$ & $\% \mathrm{CV}$ & Variation(\%) \\
\hline LQC $(15.0 \mathrm{ng} / \mathrm{ml})$ & 16.2 & 2.6 & 16.0 & 8.0 & -1.0 \\
\hline MQC $(2100.0 \mathrm{~g} / \mathrm{ml})$ & 2282.0 & 2.5 & 2357.0 & 1.6 & 3.3 \\
\hline HQC $(4200.0 \mathrm{ng} / \mathrm{ml})$ & 4380.2 & 3.0 & 4213.2 & 2.7 & 5.3 \\
\hline
\end{tabular}

Table 2: Freeze and thaw stability test.

\begin{tabular}{|l|c|l|l|l|l|}
\hline & Initial mean conc. $(\mathrm{ng} / \mathrm{ml})$ & $\% \mathrm{CV}$ & $\begin{array}{l}\text { Final mean conc. } \\
(\mathrm{ng} / \mathrm{ml})\end{array}$ & $\%$ CV & Variation $(\%)$ \\
\hline LQC $(15.0 \mathrm{ng} / \mathrm{ml})$ & 15.0 & 4.1 & 15.7 & 3.4 & 4.6 \\
\hline MQC $(2100.0 \mathrm{ng} / \mathrm{ml})$ & 2242.8 & 1.9 & 2273.7 & 2.9 & 1.4 \\
\hline HQC $(4200.0 \mathrm{ng} / \mathrm{ml})$ & 4126.3 & 3.9 & 4462.5 & 3.0 & 8.1 \\
\hline
\end{tabular}

Table 3: Long-term storage stability of cimetidine in human plasma at low and high QC samples. 


\section{Journal of Bioanalysis \& Biomedicine - Open Access \\ JBABM/Vol.1 Issue 1}

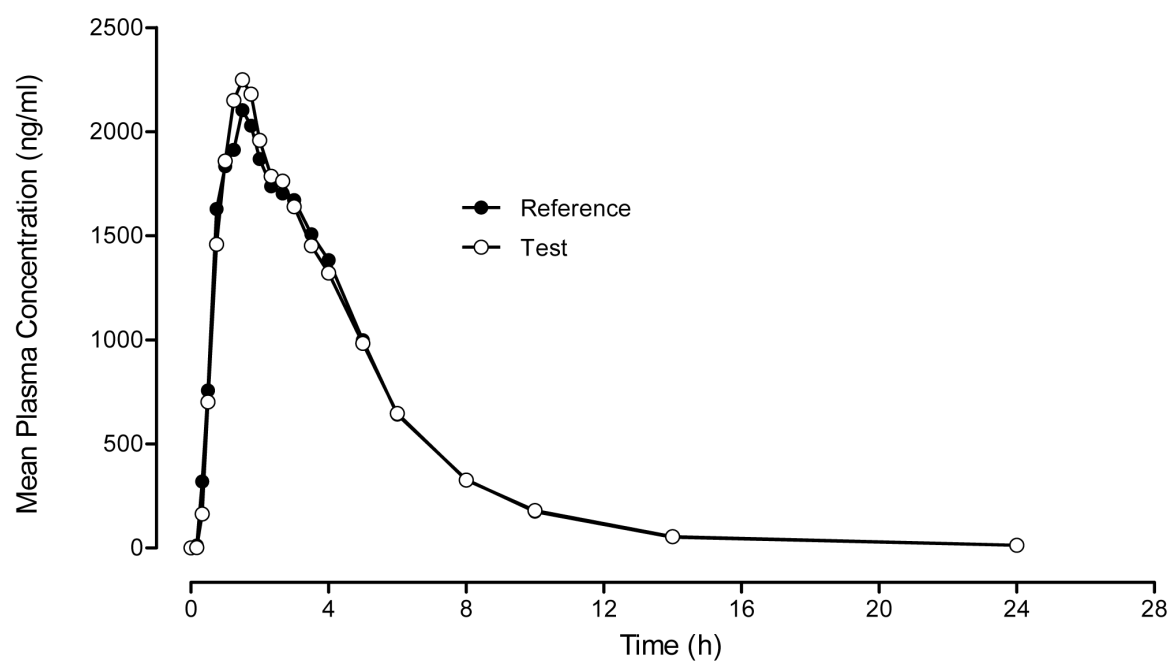

Figure 4: Cimetidine plasma mean concentration versus time profiles obtained after the single oral administration of 400 mg of cimetidine test or reference formulations.

\begin{tabular}{|l|l|l|l|l|}
\hline \multirow{2}{*}{} & Cimetidine $2.0 \mathrm{mg}$ & Reference \\
\cline { 2 - 5 } & Mean & SD & Mean & SD \\
\hline $\mathrm{C}_{\max }(\mathrm{ng} / \mathrm{ml})$ & 2814.5 & 738.2 & 2946.3 & 2698.3 \\
\hline $\mathrm{T}_{\max }(\mathrm{h})$ & 1.6 & 0.7 & 1.8 & 1.0 \\
\hline $\mathrm{T}_{1 / 2}(\mathrm{~h})$ & 3.3 & 0.6 & 3.3 & 0.6 \\
\hline $\mathrm{AUC}_{0-\mathrm{t}}([\mathrm{ng} \times \mathrm{h}] / \mathrm{ml})$ & 10393.3 & 2524.3 & 10327.9 & 2330.1 \\
\hline $\mathrm{AUC}_{\text {inf }}([\mathrm{ng} \times \mathrm{h}] / \mathrm{ml})$ & 10464.6 & 2533.1 & 10395.0 & 2334.7 \\
\hline
\end{tabular}

Table 4: Arithmetic mean (or median) pharmacokinetic parameters of cimetidine for test and reference preparations in 29 human volunteers after administration of each $400 \mathrm{mg}$ cimetidine tablet formulation.

\begin{tabular}{|c|c|c|c|c|}
\hline Cimetidine/Reference & \multicolumn{4}{|c|}{ Parametric $(n=29)$} \\
\hline & Geometric mean (\%) & $90 \% \mathrm{CI}$ & Power (\%) & $\mathrm{CV}(\%)$ \\
\hline $\mathrm{AUC}_{0-\mathrm{t}} \%$ ratio & 100.80 & $95.98-105.96$ & 99 & 11.03 \\
\hline $\mathrm{AUC}_{\text {inf }} \%$ ratio & 100.90 & $96.06-105.88$ & 99 & 10.85 \\
\hline $\mathrm{C}_{\max } \%$ ratio & 95.73 & $87.76-104.43$ & 99 & 19.51 \\
\hline
\end{tabular}

Table 5: Geometric means of individual pharmacokinetics parameters AUClast, AUC0-inf and Cmax ratios (test/reference formulation) and the respective $90 \%$ confidence intervals (CIs).

\begin{tabular}{|l|r|r|r|r|r|r|r|r|r|}
\hline & \multicolumn{5}{|c|}{ Male (n=13) } & \multicolumn{4}{|c|}{ Female (n=16) } \\
\hline & Test & SD & Ref. & SD & & Test & SD & Ref. & SD \\
\hline $\mathrm{T}_{\max }$ & 1.5 & 0.6 & 2.0 & 1.0 & & 1.7 & 0.8 & 1.7 & 1.2 \\
\hline $\mathrm{C}_{\max }$ & 2616.1 & 628.9 & 2746.1 & 808.7 & & 2975.7 & 799.4 & 3109.0 & 818.6 \\
\hline AUC $_{\text {inf }}$ & 9295.5 & 1261.0 & 9766.8 & 1657.3 & & 11285.3 & 2954.5 & 10783.8 & 2728.3 \\
\hline AUC $_{\text {inf }} /$ Cmax & 3.6 & 0.7 & 3.6 & 1.3 & & 3.8 & 0.8 & 3.5 & 0.9 \\
\hline
\end{tabular}

Table 6: Comparison of the pharmacokinetics parameters between the male e female groups after administration of test or reference 400 mg cimetidine tablet formulation.

\section{Application of the method}

Cimetidine was well tolerated at the administered doses and no significant adverse reactions were observed or reported. No clinically relevant change was observed in any measured biochemical parameter. A total of 29 volunteers finished the study. The mean cimetidine plasma concentration vs time curves obtained after a single oral dose of each formulation are shown in Figure 4. The plasma concentration of cimetidine did not differ significantly after administration of both formulations (test and the reference one).

Table 4 shows the values of the pharmacokinetic parameters and Table 5 summarizes the bioequivalence analysis for cimetidine formulations. Briefly, the geometric mean and respec- tive $90 \%$ CI of cimetidine test/reference percent ratios were $95.73 \%(87.76-104.43 \%)$ for $\mathrm{C}_{\max }$ and $100.80 \%$ (95.98 $105.96 \%$ ) for $\mathrm{AUC}_{0-\mathrm{t}}$.

The non-parametric analysis of $\mathrm{T}_{\max }$ and the $\mathrm{C}_{\max }$ differences between the male e female groups was evaluated using the Kruskal-Wallis Test. The $\mathrm{p}$ values for $90 \% \mathrm{CI}$ were 0.14 and 0.93 for $\mathrm{T}_{\text {max }}$ and $\mathrm{C}_{\text {max }}$, respectively, indicating that there are no significant differences between the male and the female group. The table 6 shows the results for $\mathrm{T}_{\max }, \mathrm{C}_{\max }$ and $\mathrm{AUC}_{\mathrm{inf}}$ for both groups.

\section{Discussion}

In this study we used the highly specific and sensitive HPLC 
Citation: Moreno RA, CostaI O, Brum Junior L, Sverdloff CE, Domingues CC, et al. (2009) Cimetidine Quantification in Human Plasma by High-performance Liquid Chromatography Coupled to Electrospray Ionization Tandem Mass Spectrometry. Application to a Comparative Pharmacokinetics Study. J Bioanal Biomed 1: 005-013. doi:10.4172/1948-593X.1000002

coupled to the electrospray ionization tandem mass spectrometric technique (LC-MS-MS), allowing a rapid chromatographic separation followed by a sensitive identification and quantification of cimetidine in human plasma.

The detection parameters in the MS system for the ESI interface were optimized preliminarily by evaluating the signal intensities and fragmentations in a series of continuous-infusion experiments. The SRM technique was also able to effectively eliminate background chemical interference arising from the complex plasma matrix. After defining the best conditions, we investigated the analytical characteristics of the developed method, including their reproducibility and limit of quantification, to evaluate its efficiency and the possibility of applying it to the analysis of samples originated from pharmacokinetics studies. This quantification method showed excellent linearity, precision and accuracy with a very broad dynamic range of 5 to $5,000 \mathrm{ng} / \mathrm{ml}$. All the validation parameters were in accordance to Food and Drug Administration (FDA) and the National Sanitary Surveillance Agency (ANVISA) requirements for pharmacokinetic studies, including the recovery, accuracy, precision and stability of cimetidine molecule during the quantification process. Xu et al., (1999) described a LC-MS-MS method using atmospheric pressure chemical ionization (APCI) describing the same $5 \mathrm{ng} / \mathrm{ml}$ limit of quantification, but the chromatography run was longer than our method. In addition, the sample preparation method described here is a very simple and fast liquidliquid extraction, providing a clean and reproducible extracted sample in accordance with the need for high throughput analysis. Additionally, a LC-MS based method was developed for the determination of cimetidine in cat plasma with a limit of quantification of $10 \mathrm{ng} / \mathrm{ml}$, twice higher than our method (Heeb et al., 2005).

The LC-MS-MS method as the described in this work has demonstrated several advantages over the previous existing HPLC/UV and CE/UV techniques. In this case, our method is at least 10 times more sensitive. The best methods described in the literature showed a limit of quantification in the range of $50 \mathrm{ng} /$ $\mathrm{ml}$ (Kelly et al., 1995; Zendelovska et al., 2003) to $100 \mathrm{ng} / \mathrm{ml}$ (Hempenius et al., 1998; Iqbal et al., 2004; Jantratid et al., 2007). In addition, all those methods used much longer chromatographic run times, ranging from 8 to $15 \mathrm{~min}$. The chromatographic run is critical in a pharmacokinetic study where hundreds or even thousands of samples need to be analyzed in a short period of time.

Since our method is suitable for supporting environmental responsiveness and, altogether, very appropriate for quantitative high-throughput analysis and therapeutic drug monitoring, it has been successfully used to analyze samples from a comparative pharmacokinetic study following oral administration of $400 \mathrm{mg}$ of cimetidine in human volunteers of both the market leader and a generic equivalent cimetidine formulation. The pharmacokinetic parameters obtained are in good agreement with a previous report (Jantratid et al., 2007; Kelly et al., 1995; Luo et al., 2001; Somogyi et al., 1983) and demonstrated that both formulations were bioequivalent. No statistical differences of $\mathrm{T}_{\text {max }}$ and the $\mathrm{C}_{\max }$ were observed related to the sex of the volunteer.

\section{Conclusion}

An LC-MS-MS method for the quantification of the cimetidine in human plasma was developed and validated using electrospray ionization mode. This method offers a simple sample extraction and only LLE is needed without any further clean-up procedures for a fast run time and performance advantages over those previously reported.

The assay performance results indicate that the method is precise and accurate enough for the routine determination of the cimetidine in human plasma and agrees with the requirements for pharmacokinetic assays such as bioequivalence studies. Since the $90 \%$ CI for Cmax and AUC ratios were all inside the 80$125 \%$ interval proposed by the US Food and Drug Administration, it was concluded that the cimetidine test formulation is bioequivalent to the reference formulation with respect to both the rate and the extent of absorption.

\section{References}

1. Abdel-Rahim M, Ezra D, Peck C, Lazar J (1985) Liquid-chromatographic assay of cimetidine in plasma and gastric fluid. Clin Chem 31: 621-623. »CrossRef » PubMed » Google Scholar

2. Berardi RR, Tankanow RM, Nostrant TT (1988) Comparison of famotidine with cimetidine and ranitidine. Clin Pharm 7: 271-284. » CrossRef » PubMed » Google Scholar

3. Chiou R, Stubbs RJ, Bayne WF (1986) Determination of cimetidine in plasma and urine by high-performance liquid chromatography. J Chromatogr 377: 441-446. » CrossRef » PubMed » Google Scholar

4. Fojo AT, Ueda K, Slamon DJ, Poplack DG, Gottesman MM, et al. (1987) Expression of a multidrug-resistance gene in human tumors and tissues. Proc Natl Acad Sci USA 84: 265-269. » CrossRef » PubMed » Google Scholar

5. Hempenius J, Wieling J, Brakenhoff JP, Maris FA, Jonkman JH (1998) Highthroughput solid-phase extraction for the determination of cimetidine in human plasma. J Chromatogr B Biomed Sci Appl 714: 361-368. » CrossRef » PubMed » Google Scholar

6. Iqbal T, Karyekar CS, Kinjo M, Ngan GC, Dowling TC (2004) Validation of a simplified method for determination of cimetidine in human plasma and urine by liquid chromatography with ultraviolet detection. J Chromatogr B Analyt Technol Biomed Life Sci 799: 337-341. » CrossRef » PubMed » Google Scholar

7. Jantratid E, Prakongpan S, Foley JP, Dressman JB (2007) Convenient and rapid determination of cimetidine in human plasma using perchloric acidmediated plasma protein precipitation and high-performance liquid chromatography. Biomed Chromatogr 21: 949-957. »CrossRef » PubMed » Google Scholar

8. Karyekar CS, Eddington ND, Garimella TS, Gubbins PO, Dowling TC (2003) Evaluation of P-glycoprotein-mediated renal drug interactions in an MDR1MDCK model. Pharmacotherapy 23: 436-442. »CrossRef » PubMed » Google Scholar

9. Kelly MT, McGuirk D, Bloomfield FJ (1995) Determination of cimetidine in human plasma by high-performance liquid chromatography following liquid-liquid extraction. J Chromatogr B Biomed Appl 668: 117-123. »CrossRef » PubMed » Google Scholar

10. Larsen NE, Hesselfeldt P, Rune SJ, Hvidberg EF (1979) Cimetidine assay in human plasma by liquid chromatography. J Chromatogr 163: 57-63. »CrossRef » PubMed » Google Scholar

11. Lin Q, Lensmeyer GL, Larson FC (1985) Quantitation of cimetidine and cimetidine sulfoxide in serum by solid-phase extraction and solvent-recycled liquid chromatography. J Anal Toxicol 9: 161-166. »CrossRef » PubMed » Google Scholar

12. Lorenzo B, Drayer DE (1981) Improved method for the measurement of cimetidine in human serum by reverse-phase high-pressure liquid chromatography. J Lab Clin Med 97: 545-550. » CrossRef » PubMed » Google Scholar

13.Luksa J, Josic D (1995) Determination of cimetidine in human plasma by 


\section{Journal of Bioanalysis \& Biomedicine - Open Access JBABM/Vol.1 Issue 1}

free capillary zone electrophoresis. J Chromatogr B Biomed Appl 667: 321327. » CrossRef » PubMed » Google Scholar

14. Luo JW, Chen HW, He QH (2001) Determination of Cimetidine in Human Plasma by Use of Coupled-Flow Injection, Solid-Phase Extraction, and Capillary Zone Electrophoresis. Chromatographia 53: 295-300. »CrossRef » PubMed » Google Scholar

15. Pedersen PV, Miller R (1980) Pharmacokinetics and bioavailability of cimetidine in humans. J Pharm Sci 69: 394-398. » CrossRef » PubMed » Google Scholar

16. Russel FG, Creemers MC, Tan Y, van Riel PL, Gribnau FW (1994) Ion-pair solid-phase extraction of cimetidine from plasma and subsequent analysis by high-performance liquid chromatography. J Chromatogr B Biomed Appl 661: 173-177. »CrossRef » PubMed » Google Scholar

17. Soldin SJ, Fingold DR, Fenje PC, Mahon WA (1979) High performance liquid chromatographic analysis of cimetidine in serum. Ther Drug Monit 1: 371-379. » CrossRef » PubMed » Google Scholar

18. Somogyi A, Gugler R (1983) Clinical pharmacokinetics of cimetidine. Clin Pharmacokinet 8: 463-495. » CrossRef » PubMed » Google Scholar
19. Somogyi A, Gugler R (1982) Drug interactions with cimetidine. Clin Pharmacokinet 7: 23-41. »CrossRef » PubMed » Google Scholar

20. Strong HA, Spino M (1987) Highly sensitive determination of cimetidine and its metabolites in serum and urine by high-performance liquid chromatography. J Chromatogr 422: 301-308. »CrossRef » PubMed » Google Scholar

21. Thiebaut F, Tsuruo T, Hamada H, Gottesman MM, Pastan I, et al. (1987) Cellular localization of the multidrug-resistance gene product P-glycoprotein in normal human tissues. Proc Natl Acad Sci USA 84: 7735-7738. »CrossRef » PubMed » Google Scholar

22. Xu K, Arora VK, Chaudhary AK, Cotton RB, Blair IA (1999) Quantitative analysis of cimetidine in human plasma using LC/APCI/SRM/MS. Biomed Chromatogr 13: 455-461. » CrossRef » PubMed » Google Scholar

23.Zendelovska D, Stafilov T (2003) Development of an HPLC method for the determination of ranitidine and cimetidine in human plasma following SPE. J Pharm Biomed Anal 33: 165-173. » CrossRef » PubMed » Google Scholar

24.Ziemniak JA, Chiarmonte DA, Schentag JJ (1981) Liquid-chromatographic determination of cimetidine, its known metabolites, and creatinine in serum and urine. Clin Chem 27: 272-275. » CrossRef » PubMed » Google Scholar 